\title{
Strategi Bisnis Jangka Panjang Dalam Menghadapi Persaingan Antar Pengusaha Home Industry Masyarakat Pesisir di Desa Tanjungsari Kendal
}

\author{
Susanti $^{1)}$, Masriah $^{2)}$ \\ ${ }^{1)}$ Politeknik Maritim Negeri Indonesia \\ Jl. Pawiyatan Luhur I/1, Bendan Duwur, Semarang, Indonesia 50233 \\ Email : susanti@polimarin.ac.id ${ }^{1)}$, masriah@polimarin.ac.id ${ }^{2)}$
}

\begin{abstract}
Abstrak
Strategi bisnis bertujuan untuk mencapai tujuan jangka panjang yang ingin dicapai dan menemukan posisi dalam industri rumahan (home industry) sehingga usaha industri rumahan dapat melindungi dirinya terhadap tekanan persaingan. Penelitian ini bertujuan untuk mengembangkan strategi usaha yang sudah dimiliki oleh industri rumahan sehingga usaha industri rumahan dapat bertahan dari tekanan persaingan yang semakin ketat di pasar. Metode yang digunakan dalam penelitian ini metode kualitatif deskriptif. Teknik pengumpulan data dilakukan dengan metode wawancara semi terstruktur dengan menggunakan purposive sampling dalam memilih narasumber. Dalam menguji validitas data dalam penelitian ini dilakukan dengan menganalisa lingkungan eksternal menggunakan lingkungan internal melalui fungsi bisnis. Kemudian melakukan analisis SWOT dan di matrikskan sehingga dapat menghasilkan beberapa alternatif dalam mengembangkan strategi bisnis untuk Industri rumahan olahan ikan. Strategi yang tepat bagi perusahaan dalam hasil penelitian ini yaitu strategi agresif. Dengan strategi alternatif tersebut perusahaan dapat mencapai tujuan yang diinginkan serta dapat bertahan dalam menghadapi tekanan persaingan yang ada.
\end{abstract}

Kata Kunci: Analisis Eksternal Lingkungan, Analisis Internal Lingkungan , Bisnis Strategi, Home Industri

\begin{abstract}
Business strategy aims to achieve the long-term goals to be achieved and find a position in the home industry so that the household industry business can protect itself against the pressures of competition. This research aims to develop business strategy that already owned by the home industry so that the home industry business can withstand the pressures of increasingly intense competition in the market. This research uses qualitative methods of descriptive. Data collection techniques are done by semi-structured interview methods using purposive sampling in selecting speakers. In testing the validity of the data in this study was conducted by analyzing the external environment using internal environment through business function. In testing the validity of the data in this study was conducted by analyzing the external environment using internal environment through business function. The right strategy for the company in the results of this research is aggressive strategy. With the alternative strategy the company can achieve the desired objectives and can withstand the pressure of existing competition
\end{abstract}

Key words: Analysis External Environmental, Analysis Internal Environmental Bisnis Strategy, Home Industry 


\section{PENDAHULUAN}

Kabupaten Kendal sebagai daerah pesisir memiliki potensi sumber daya alam sangat besar untuk menjadi pengembangan industri rumahan berbasis sumber daya alam. Seiring dengan upaya meningkatkan kesejahteraan keluarga dengan melibatkan kaum perempuan menjadi terbukanya akses terhadap sumber daya ekonomi. Dalam mendukung kekuatan ekonomi keluarga kaum wanita mempunyai peran yang sangat besar dalam skala usaha mikro industri rumahan.

Kabupaten Kendal telah menjadi pilot proyek dalam pengembangan industri rumahan sebagian pelaku usahanya perempuan. Home Industry atau Industri Rumahan (IR) adalah merupakan peluang usaha yang banyak bermunculan dalam era sekarang dikarenakan semakin sempitnya lapangan pekerjaan yang tersedia.

Industri rumahan yang berkembang di Kabupaten Kendal adalah industri rumahan dalam bidang makanan, terutama pengolahan ikan seperti pengasapan ikan dan pemindangan ikan serta bandeng presto.

Desa Tanjungsari, kecamatan Rowosari sebagai sentra produksi pengasapan ikan dan pemindangan ikan. Lokasi desa yang tidak jauh dari pantai dan tempat pelelangan ikan, sehingga bahan baku ikan segar cukup berlimpah.

Menurut Kepala Desa Tanjungsari, bapak Sugianto, mayoritas warganya berprofesi sebagai pedagang ikan, sehingga setiap rumah memproduksi ikan asap dan pindang. Ada sekitar 400 industri rumahan yang membuat produksi olahan ikan.

Dalam penelitian ini masyarakat Desa Tanjungsari dalam menghadapi persaingan antar pengusaha industri rumahan perlu adanya suatu strategi bisnis yang terpadu dan tepat,agar tetap mampu bertahan dalam menghadapi persaingan. Untuk itu peneliti memilih penekanan pada faktor kekuatan dan kelemahan yang terdapat dalam usaha industri rumahan sedangkan peluang dan ancaman merupakan faktor lingkungan yang dihadapi oleh usaha industri rumahan

Industri rumahan walaupun nampaknya kecil namun kalau dipahami dan dikembangkan dapat meningkatkan penghasilan warga masyarakat. Industri rumahan sangat potensial dan bisa menghasilkan pendapatan yang besar apabila dikelola dengan baik secara profesional. Pengangguran dan kemiskinan dapat dikurangi dengan mengoptimalkan industri rumahan dan atau merintis industri rumahan yang baru.

Penelitian terdahulu Marketing Development Strategy of Home Industry Raflesia at Sumber Agung Village Atma Jaya Sub District Bengkulu (Dwi Lestari dkk) persamaan membahas tentang Industri Rumahan sedang perbedaannya Strategi digunakan metode Analytik Hierarchy Process (AHP) sedang penelitian yang dilakukan saat ini strategi yang digunakan Analisis SWOT.Dalam perkembangan usaha industri rumahan diperlukan strategi bisnis yang tepat untuk diterapkan, hal ini perlu adanya Strategi bisnis yang sesuai dalam menghadapi persaingan antar pengusaha Industri Rumahan. Oleh karena itu, perlu kajian terhadap pengembangan jangka panjang usaha ini.

Tujuan penelitian adalah identifikasi faktor internal dan eksternal dan mengetahui strategi yang tepat untuk diterapkan dalam menghadapi persaingan antar pengusaha industri rumahan. Sedang manfaatnya bagi

industri rumahan memberikan pengetahuan tentang strategi bisnis yang merupakan suatu hal yang penting dalam melakukan kegiatan usaha dengan maksud mendapatkan keuntungan dan kemampuan bersaing dengan segmentasi dan pangsa pasar yang diharapkan

\section{METODE PENELITIAN}

Penelitian ini menggunakan metode penelitian deskriptif kualitatif. Penelitian deskriptif merupakan metode penelitian yang berusaha menggambarkan suatu obyek sesuai dengan keadaan atau apa adanya. Metode yang digunakan dalam penelitian ini adalah dengan cara mengambil data primer dan data sekunder. pengamatan peneliti terhadap obyek penelitian sehingga dapat mengetahui dan memahami kondisi yang sebenarnya. Informasi didapatkan dengan mendatangi langsung atau melakukan pengamatan di sentra industri rumahan pengolahan ikan di desa Tanjungsari Kecamatan Rowosari Kabupaten Kendal untuk melihat kodisi dan permasalahan secara terperinci dan untuk mengetahui kegiatan, gambaran umum yang terjadi di sekitar industri tersebut. Dalam penelitian ini menggunakan teknik kuesioner yang dibagi menjadi dua yaitu kuesioner pertama digunakan peneliti untuk memberikan nilai bobot dari faktor internal dan eksternal sentra industri rumahan pengolahan ikan desa Tanjungsari, kuesioner ini nantinya diisi oleh pengrajin pengolahan ikan. Kuesioner kedua digunakan peneliti untuk mendapatkan nilai peringkat (rating) dari faktor internal dan eksternal sentra industri rumahan pengolahan ikan desa Tanjungsari

\section{Metode Analisis Data}

Dalam penelitian ini metode analisis data yang digunakan adalah metode secara deskriptif kuantitatif dengan menggunakan analisis SWOT yang merupakan sebuah metode perencanaan strategi yang digunakan untuk merumuskan suatu strategi yang dapat memaksimalkan kekuatan (strenghs) dan peluang (opportunities) secara bersamaam dapat meminimalkan kelemahan (weakness) dan ancaman (threats) mengevaluasi kekuatan, kelemahan, peluang dan ancaman dalam suatu spekulasi bisnis. Melalui analisis SWOT menenukan alternatif strategi yang paling tepat untuk diterapkan oleh industri. Dalam merumuskan strategi perusahaan, analisis yang digunakan adalah matriks IFAS dan EFAS, Matriks IE, matriks SWOT dan Matrik Diagram SWOT (David, 2012 : 324) 
Obyek Penelitian

metode yang digunakan adalah deskriptif kualitatif, ini dilakukan pada industri rumahan pengolahan ikan di desa Tanjungsari kecamatan Rowosari Kabupaten Kendal, Sedanglan metode analisis yang digunakan adalah analisis deskriptif kuantitatif yaitu metode analisis SWOT

\section{HASIL DAN PEMBAHASAN}

Identifikasi Faktor Internal dan Faktor Eksternal

3.1. Faktor Internal

\section{Kekuatan (Strenghths)}

1) Bahan baku yang mudah didapat

2) Harga bahan baku yang relatif murah

3) Kualitas bahan baku baik

4) Telah mengikuti pelatihan kerampilan

5) Tingkat kesulitan yang rendah

6) Produk yang dihasilkan tahan lama

7) Harga jual yang terjangkau

Kelemahan (Weakness)

1) Belum memiliki pencatatan keuangan

2) Alat produksi yang masih tradisional

3) Pengemasannya kurang higienis masih menggunakan kertas bekas atau koran

4) Belum memiliki metode promosi produk lewat online

5) Belum menggunakan proses produksi dengan teknologi modern

6) Tidak memiliki tempat parkir

\subsection{Faktor Eksternal}

Peluang (Opportunities)

1) Peningkatan permintaan dari pembeli lokal maupun luar kota

2) Kesempatan mengikuti pameran

3) Potensi dan peluang pasar sangat luas

Ancaman (Threats)

1) Kurangnya minat generasi muda untuk bekerja dalam meneruskan dan mempertahankan usaha industri rumahan pemindangan dan pengasapan ikan

2) Adanya pesaing baru

3) Tempat usaha (di rumah) yang kurang memperhatikan kesehatan terutama yang pengrajin pengasapan ikan karena asapnya akan mengganggu pernafasan

Tabel 1. Kuesioner Internal Faktor Analisis Strategi untuk mengetahui Kekuatan (Strenght)

\begin{tabular}{lccc}
\multicolumn{1}{c}{ Faktor Strategis } & Bobot & Rating & Skor \\
\hline $\begin{array}{l}\text { Mampu memproduksi Ikan pindang, } \\
\text { Ikan asap dan ikan bandeng presto } \\
\text { dengan volume terus meningkat }\end{array}$ & 0,26 & 4 & 1,04 \\
\hline $\begin{array}{l}\text { Mampu menjual produknya di luar } \\
\text { kota kendal melalui jaringan } \\
\text { distribusi di Wonosobo dan } \\
\text { Temanggung }\end{array}$ & 0,22 & 3,5 & 0,77 \\
\hline $\begin{array}{l}\text { Mempunyai keahlian dalam } \\
\text { Pengasapan dan pemindangan ikan }\end{array}$ & 0,26 & 4 & 1,04 \\
\hline Harga terjangkau & 0,26 & 5 & 1,3 \\
\hline Total nilai & $\mathbf{1}$ & & $\mathbf{4 , 1 5}$ \\
\hline
\end{tabular}

Sumber : Data primer setelah diolah 
Tabel 2. Kuesioner Internal Faktor Analisis Strategi untuk mengetahui Kelemahan(Weakness)

\begin{tabular}{lccc}
\hline \multicolumn{1}{c}{ Faktor Strategis } & Bobot & Rating & Skor \\
\hline $\begin{array}{l}\text { Modal dan total aset yang dipunyai pemilik tidak } \\
\text { pernah dilakukan pembukuan sehingga tidak } \\
\text { mengetahui perkembangan kinerja Industri } \\
\text { rumahan pengolahan ikan }\end{array}$ & 0,27 & 2 & 0,54 \\
\hline $\begin{array}{l}\text { Dalam produksi yang dihasilkan tidak begitu } \\
\text { banyak mengingat penggunaan teknologi masih } \\
\text { tradisional. }\end{array}$ & 0,27 & 2 & 0,54 \\
\hline $\begin{array}{l}\text { Variasi produk seperti, Ikan asap, ikan pindang, } \\
\text { bandeng presto }\end{array}$ & 0,19 & 2 & 0,38 \\
\hline $\begin{array}{l}\text { Fasilitas pendukung kegiatan pengolahan ikan } \\
\text { belum tersedia seperti gedung pengolahan ikan } \\
\text { chilling room }\end{array}$ & 0,27 & 2,5 & 0,68 \\
\hline Total nilai & & & \\
\hline Sumber : Data primer setelah & & & 2,14 \\
\hline
\end{tabular}

Sumber : Data primer setelah diolah

Tabel 3. Kuesioner Eksternal Faktor Analisis Strategi untuk mengetahui Peluang(Opportunity)

\begin{tabular}{lccc}
\hline \multicolumn{1}{c}{ Faktor Strategis } & Bobot & Rating & Skor \\
\hline $\begin{array}{l}\text { Dukungan pemerintah Kota kendal dengan } \\
\text { arah kebijakan pengembangan Desa }\end{array}$ & 0,375 & 4 & 1,5 \\
$\begin{array}{l}\text { Industrirumahan olahan ikan } \\
\text { Dukungan pemerintah nasional melalui } \\
\text { kebijakan gemar makan ikan dan } \\
\text { peningkatan modal investasi untuk industri } \\
\text { rumahan pengasapan dan pemindangan } \\
\text { ikan }\end{array}$ & 0,375 & 3 & 1,125 \\
\hline $\begin{array}{l}\text { Dukungan masyarakat sekitar dengan } \\
\text { adanya industri rumahan untuk } \\
\text { meningkatkan lapangan pekerjaan }\end{array}$ & & & \\
\hline Total nilai & 0,25 & 2 & 0,5 \\
\hline Sumber: Data primer setelah diolah & & & \\
\hline
\end{tabular}

Sumber : Data primer setelah diolah

Tabel 4.Kuesioner Eksternal Faktor Analisis Strategi untuk mengetahui Ancaman(Threath)

\begin{tabular}{lccc}
\hline \multicolumn{1}{c}{ Faktor Strategis } & Bobot & Rating & Skor \\
\hline $\begin{array}{l}\text { Kurangnya minat generasi muda untuk } \\
\text { bekerja dalam meneruskan dan } \\
\text { mempertahankan usaha industri rumahan } \\
\text { pemindangan dan pengasapan ikan }\end{array}$ & 0,375 & 3 & 1,125 \\
\hline Pesaing baru & & & \\
\hline $\begin{array}{l}\text { Tempat usaha yang kurang memperhatikan } \\
\text { kesehatan terutama yang pengolahan pengasapan } \\
\text { ikan karena asapnya akan mengganggu pernafasan }\end{array}$ & 0,375 & 25 & $.1,5$ \\
\hline Total nilai & 1 & & 0,375 \\
\hline Sumber : Data primer setelah diolah & & & 2,25 \\
\hline
\end{tabular}

Strategi Pengembangan Pengolahan Industri Rumahan Pengolahan ikan di Desa Tanjungsari

\section{Hasil Evaluasi Lingkungan Internal}

Berdasarkan hasil matriks IFAS dapat dilihat bahwa faktor strategis internal kekuatan memiliki skor sebesar 4,15 sedang faktor strategis internal kelemahan memiliki nilai skor sebesar 2,14 Hal ini menunjukkan bahwa faktor kekuatan lebih tinggi dibandingkan faktor kelemahan.

\section{Hasil Evaluasi Lingkungan Eksternal}

Berdasarkan hasil matriks EFAS pada faktor strategis eksternal peluang memiliki nilai skor 3,125sedang nilai faktor strategis eksternal ancaman memiliki skor sebesar 2,25 .hal ini berarti industri rumahan pengolahan ikan yang 
ada di desa Tanjungsari memiliki peluang yang lebih besar untuk mengantisipasi ancaman dalam menentukan strategi pengembangannya.

\subsection{Diagram SWOT}

Hasil perhitungan nilai skor faktor strategis internal yaitu faktor kekuatan dkurangi faktor kelemahan diperoleh nilai $\mathrm{x}$ sebagai sumbu horisontal $=4,15-2,14=2,01$. Dengan demikian nilai sumbu $\mathrm{x}$ dalam diagram SWOT adalah sebesar 2,01. kemudian hasil perhitungan nilai skor faktor strategis eksternal yaitu peluang dikurangi ancaman $=3,125-2,25=0$, 875. Hasil perhitungan nilai skor faktor strategis eksternal yaitu peluang dikurangi ancaman diperoleh nilai y dalam diagram SWOT adalah sebesar 0,875.

Faktor strategis Internal

Faktor strategis Eksternal

kekuatan > kelemahan $(2,01)$

peluang >ancaman $(0,875)$

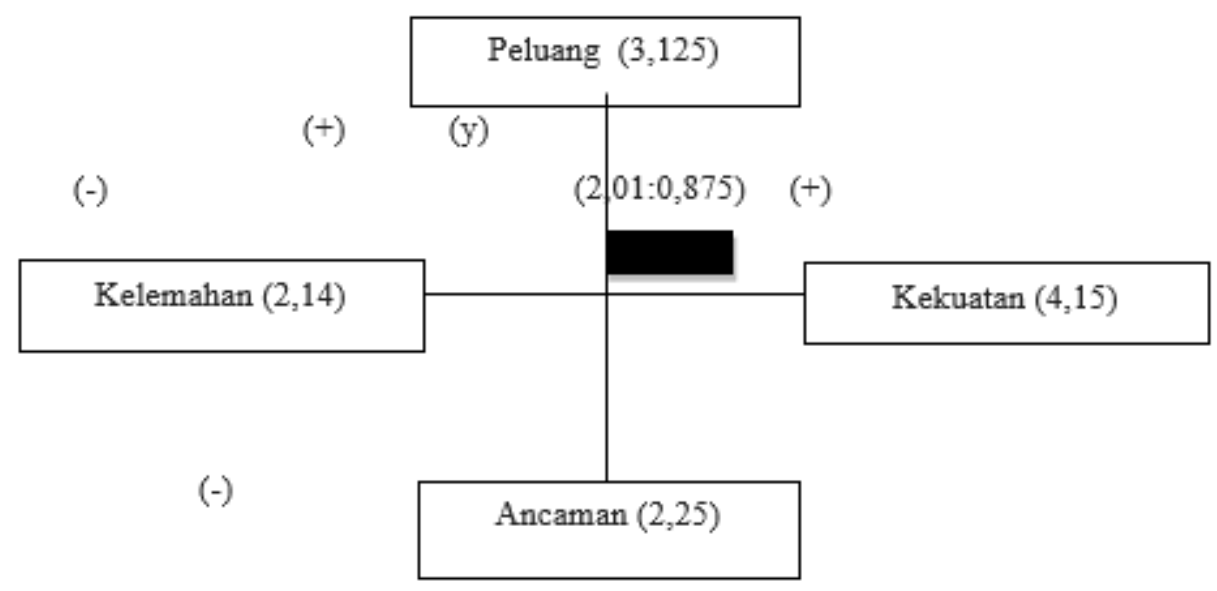

Gambar 1. Diagram SWOT

Diagram SWOT tersebut menunjukkan bahwa posisi industi rumahan pengolahan ikan desa Tanjungsari berada pada kuadran 1(satu), artinya memiliki peluang dan kekuatan sehingga dapat memafaatkan peluang yang ada. Strategi yang harus diterapkan adalah mendukung kebijakan pertumbuhan yang agresif (growthrientid strategy).

\subsection{Matriks SWOT}

1) Strategi SO:

a. Mengembangkan produk-olahan ikan dengan cara berinovasi untuk menciptakan atau menghasilkan produk olahan ikan dengan desain yang baru.

b. Bekerja sama dengan pemerintah untuk terus memperluas jaringan pemasaran atau daerah pemasaran.

2) Strategi WO:

a. Mempertahankan kesetiaan konsumen dengan memperbaiki sarana-sarana penunjang,

b. display produk,

c. meningkatkan kualitas produk dengan menggunakan teknologi dan berupaya untuk memperkenalkan produk lebih luas lagi.

3) Strategi ST:

a. Memberikan pelatihan kepada generasi muda untuk mewarisi budaya pengolahan ikan atau mempertahankan keberlanjutan industri rumahan,

b. Menjaga kualitas produk untuk menghadapi persaingan yang ada terutama terhadap produk-produk dengan pengemasan yang higienis dan tahan lama.

4) Strategi WT:

a. Bekerja sama dengan pemerintah setempat untuk membina generasi muda lewat budaya pengolahan ikan,

b. Bekerja sama dengan pemerintah dalam mengupayakan pengadaan mesin produksi,

c. Bekerja sama dengan pemerintah untuk membangun sarana pemasaran dan relokasi kegiatan pengolahan ikan yaitu pengasapan dan pemindangan ikan

Posisi industi rumahan pengolahan ikan dalam diagram SWOT menunjukkan bahwa usaha ini berada pada kuadran 1 (satu) artinya strategi yang tepat untuk digunakan dalam industri rumahan pengolahan ikan di desa Tanjungsari adalah 
strategi SO, dengan tetap meninjau atau memperhatikan tiga strategi lainnya yaitu strategi WO, strategi ST dan strategi WT.

\section{KESIMPULAN}

Berdasarkan hasil analisis dan pembahasan atas masalah yang telah dikemukakan sebelumnya, maka dapat ditarik kesimpulan dari hasil analisis yaitu : 1) berdasarkan hasil matriks IFAS dapat dilihat bahwa faktor strategis internal, kekuatan memiliki skor sebesar 4,15 sedang faktor strategis internal, kelemahan memilki nilai skor sebesar 2,14. Hal ini menunjukkan bahwa faktor kekuatan lebih tinggi dibandingkan faktor kelemahan.2) Berdasarkan hasil matrik EFAS pada faktor strategis eksternal peluang memiliki nilai skor 3,125 sedang nilai faktor strategis eksternal ancaman memiliki skor sebesar 2,25, hal ini berarti industri rumahan pengolahan ikan yang ada di desa Tanjungsari memiliki peluang yang lebih besar untuk mengantisipasi ancaman dalam menentukan strategi pengembangannya. 3) berdasarkan diagram SWOT menunjukkan bahwa posisi industri rumahan pengolahan ikan Desa Tanjungsari berada pada kuadran 1 (satu) artinya memiliki peluang dan kekuatan sehingga dapat memanfaatkan peluang yang ada. Strategi yang harus dierapkan adalah mendukung kebijakan pertumbuhan yang agresif (Growth Oriented Strategi) dengan memanfaatkan seluruh kekuatan untuk merebut dan memanfaatkan peluang sebesar-besarnya (Rangkuti, 2006;31) berdasarkan posisi industri rumahan pengolahan ikan untuk pengembangan bisnis/usaha industri rumahan pengolahan ikan dengan menggunakan matrik SWOT adalah strategi S-O (Strategi-Opportunities) yaitu dengan memanfaatkan kekuatan yang dimiliki industri rumahan untuk meraih peluang yang ada dengan cara melakukan pengembangan produk memperluas wilayah pemasaran dan peningkatan kualitas SDM (Yuliana , 2013) strategi SO, dengan tetap meninjau atau memperhatikan 3 (tiga) strategi lainnya yatu strategi ST dan strategi WT

\section{DAFTAR PUSTAKA}

Amalia. Alif, Wahyu Hidayat, Agung Budiatmo. 2012. Analisis Strategi Pengembangan Usaha Pada UKM Batik.Jurnal Admistrasi Bisnis vol. 1 No. 1

Budzynska, Agata. (2013). Developing Competitive Advantage on the Example of Internationalized SMEs in the Food Sector of Greater Poland Region. OeconomiA copernicana. No.4, p. 45-47.

Budzynska, Agata. (2013). Developing Competitive Advantage on the Example of Internationalized SMEs in the Food Sector of Greater Poland Region. OeconomiA copernicana. No.4, p. 45-47.

Kimbal R.W. 2015. Model Sosial dan Ekonomi Industri Kecil. Sebuah Studi Kualitatif . Yogyakarta, Penerbit Depublis. Hal. 27

Leung, B.Y.P, Hui, E.C.M, tan, J., Chen, L., Xu, W. (2011). SWOT dimensional analysis for strategic planning-The case of overseas real estate developers in Guangzhou, China. International Journal of Strategic Property Management Vol. 15(2) ; 105-122.

Moleong, Lexy J.2011. Metodologi Penelitian Kualitatif Bandung : Remaja Rosda Karya

Rahmayati HM, SWOT Analysis Determining The Marketing Strategy OF Frozen Shrimp, PT. Mstika Mina Nusa Aurora Tarakan, North Borneo. Jurnal Galung Tropika Vol 4 no 1 Januari 2015.

Rangkuti, Freddy, 2015. Analisis SWOT :Teknik membedah kasus bisnis, Jakarta : Gramedia Pustaka Utama

Riski Ananda, 2016. Peran Home Industri Dalam Meningkatkan Ekonomi Keluarga. (Studi Kasus Home Industri Keripik di Kelurahan Kubu, Gabang). Riau Jurnal JPM Fisip Vol.3 Fakultas Ilmu Sosial dan Ilmu Politik Universitas Riau. Hal.10

Pearce II, John A. \& Robinson, Richard B. Jr, 2013, Manajemen Strategis, Formulasi, Implementasi, dan Pengendalian, Edisi 12 buku 1

Pulaj, Enida, Kume, Vasilika. (2013). How the Albanian external environment affect the Construction industry. Annales Universitas Apulensis Series Oeconomica, 15(1), 2013, 295-309. 